\title{
Icariin Prevents Amyloid Beta-Induced Apoptosis via the PI3K/Akt Pathway in PC-12 Cells
}

\author{
Dongdong Zhang, ${ }^{1,2}$ Zhe Wang, ${ }^{1}$ Chenxia Sheng, ${ }^{1}$ Weijun Peng, \\ Shan Hui, ${ }^{1}$ Wei Gong, ${ }^{1}$ and Shuai Chen ${ }^{1}$ \\ ${ }^{1}$ Department of Integrated Chinese and Western Medicine, The Second Xiangya Hospital, Central South University, \\ Changsha, Hunan 410011, China \\ ${ }^{2}$ Department of Traditional Chinese Medicine, Zhong Shan Hospital Xiamen University, Xiamen, Fujian 361004, China \\ Correspondence should be addressed to Zhe Wang; ericwangzhe@126.com
}

Received 25 November 2014; Accepted 5 January 2015

Academic Editor: Ki-Wan Oh

Copyright (C) 2015 Dongdong Zhang et al. This is an open access article distributed under the Creative Commons Attribution License, which permits unrestricted use, distribution, and reproduction in any medium, provided the original work is properly cited.

Icariin is a prenylated flavonol glycoside derived from the Chinese herb Epimedium sagittatum that exerts a variety of pharmacological activities and shows promise in the treatment and prevention of Alzheimer's disease. In this study, we investigated the neuroprotective effects of icariin against amyloid beta protein fragment $25-35\left(\mathrm{~A} \beta_{25-35}\right)$ induced neurotoxicity in cultured rat pheochromocytoma PC12 cells and explored potential underlying mechanisms. Our results showed that icariin dose-dependently increased cell viability and decreased $\mathrm{A} \beta_{25-35}$-induced apoptosis, as assessed by MTT assay and Annexin V/propidium iodide staining, respectively. Results of western blot analysis revealed that the selective phosphatidylinositol 3-kinase (PI3K) inhibitor LY294002 suppressed icariin-induced Akt phosphorylation, suggesting that the protective effects of icariin are associated with activation of the PI3K/Akt signaling pathway. LY294002 also blocked the icariin-induced downregulation of proapoptotic factors Bax and caspase-3 and upregulation of antiapoptotic factor Bcl-2 in A $\beta_{25-35}$-treated PC12 cells. These findings provide further evidence for the clinical efficacy of icariin in the treatment of Alzheimer's disease.

\section{Introduction}

Alzheimer's disease (AD), the leading cause of dementia, is characterized by the progressive loss of memory and other cognitive functions [1]. Despite considerable progress towards understanding the complex molecular mechanisms underlying $\mathrm{AD}$, effective treatments able to prevent, halt, or reverse the pathobiology of $\mathrm{AD}$ are still lacking [2]. As the global population ages, the economic impact of dementia is expected to exceed that of cancer, heart disease, and stroke combined [3].

According to the amyloid hypothesis, neurodegeneration and dementia in $\mathrm{AD}$ are caused by extensive accumulation of amyloid beta peptide $(\mathrm{A} \beta)$ in the cerebrum $[4,5]$. Extracellular deposits of the $\mathrm{A} \beta$ peptide form diffuse and neuritic plaques, and the microtubule assembly protein tau becomes hyperphosphorylated, accumulating intracellularly as neurofibrillary tangles [1]. In addition, widespread loss of neurons and synapses occurs [6]. Numerous studies have demonstrated that apoptosis is the primary mechanism underlying $A \beta$-induced neuronal death [7-9]; therefore, drugs blocking apoptosis may be useful to prevent neuronal cell death and treat $\mathrm{AD}[8,10,11]$. The phosphatidylinositol 3-kinase (PI3K)/Akt pathway, which functions as a critical regulator of cell apoptosis, is thought to play an important role in neurological diseases such as $\mathrm{AD}[12,13]$.

Icariin, which is a prenylated flavonol glycoside derived from the Chinese herb Epimedium sagittatum, exerts a variety of pharmacological activities including antioxidant activity [14], immunoregulation [15], antitumor activity [16, 17], and estrogen-like activities $[18,19]$. Icariin appears to be able to cross the blood-brain barrier and provide neuroprotective effects by modulating the cholinergic system and inhibiting $\mathrm{A} \beta$ neurotoxicity [20]. Studies in mouse models of $\mathrm{AD}$ and age-related cognitive decline have demonstrated that icariin improves cognitive ability and inhibits memory impairment 
[21, 22]. In addition, Zeng et al. demonstrated that icariin reduces neurotoxicity by inhibiting tau protein hyperphosphorylation [23]; however, the mechanism underlying this effect is unknown and the effect of icariin on $A \beta$-induced apoptosis, a hallmark of $\mathrm{AD}$, remains unclear. A recent study suggested that icariin inhibits apoptosis via the PI3K/Akt pathway [24]. Therefore, in this study we evaluated the role of $\mathrm{PI} 3 \mathrm{~K} / \mathrm{Akt}$ signaling in the protective effects of icariin against $\mathrm{A} \beta$-induced apoptosis in cultured rat pheochromocytoma PC12 cells. Our results provide further evidence for the clinical efficacy of icariin in the treatment of AD.

\section{Materials and Methods}

2.1. Reagents. Icariin (purity $>98 \%$ ) was purchased from the Hunan Institute for the Control of Pharmaceutical and Biological Products (Changsha, China). The selective PI3K inhibitor LY294002 was purchased from Sigma-Aldrich (St. Louis, MO, USA), and the Annexin-V-FLUOS staining kit was purchased from Roche (Penzberg, Germany). Dulbecco's modified Eagle medium (DMEM), penicillin, and streptomycin were purchased from Solarbio (Shanghai, China), and fetal bovine serum was purchased from Invitrogen/ Gibco (Carlsbad, CA, USA). Antibodies against Akt, p-Akt (Ser473), Bax, Bcl-2, caspase-3, and $\beta$-actin were obtained from Abzoom (Dallas, TX, USA). Anti-mouse horseradish peroxide- (HRP-) conjugated IgG and anti-rabbit HRPconjugated IgG secondary antibodies were obtained from Santa Cruz Biotechnology (Santa Cruz, CA, USA).

2.2. Peptide Preparation. $\mathrm{A} \beta_{25-35}$ was dissolved in deionized distilled water at a concentration of $1 \mathrm{mM}$ and incubated at $37^{\circ} \mathrm{C}$ for $72 \mathrm{~h}$ to induce aggregation [23].

2.3. Cell Culture and Drug Treatments. PC12 cells were maintained in DMEM containing 10\% fetal bovine serum, $100 \mathrm{U} / \mathrm{mL}$ penicillin, and $100 \mathrm{U} / \mathrm{mL}$ streptomycin at $37^{\circ} \mathrm{C}$ in a $5 \% \mathrm{CO}_{2}$ incubator; the medium was changed every other day. The cells were cultured in serum-free medium for $12 \mathrm{~h}$ prior to treatment with icariin, and $\mathrm{A} \beta_{25-35}$ was added $1 \mathrm{~h}$ later. In experiments involving the inhibition of PI3K/Akt signaling, LY294002 $(50 \mu \mathrm{M})$ was added to the medium $1 \mathrm{~h}$ prior to icariin treatment.

2.4. Cell Viability Assay. PC12 cells were seeded into 96well plates $\left(0.5 \times 10^{4}\right.$ cells/well $)$ and assessed for response to $\mathrm{A} \beta_{25-35}$ and icariin using the MTT assay. Briefly, the cells were pretreated with icariin $(2.5,5.0,10.0$, or $20.0 \mu \mathrm{M})$ or vehicle only for $1 \mathrm{~h}$ and then exposed to $20 \mu \mathrm{M}$ preaggregated $\mathrm{A} \beta_{25-35}$ for $24 \mathrm{~h}$ in the continued presence of icariin or vehicle. To determine viability, the cells were then treated with $5 \mathrm{mg} / \mathrm{mL}$ MTT for $4 \mathrm{~h}$ at $37^{\circ} \mathrm{C}$ and then the medium was carefully removed. The resulting formazan crystals were dissolved in $150 \mu \mathrm{L}$ dimethyl sulfoxide (DMSO), and absorbance at $570 \mathrm{~nm}$ was determined using a plate reader.

2.5. Apoptosis Assay. Apoptosis was detected using the Annexin-V-FLUOS staining kit (Roche). Briefly, $5 \times 10^{5}$ cells were collected, resuspended in phosphate buffered saline, and incubated with Annexin V/PI labeling solution for $20 \mathrm{~min}$ at room temperature in the dark. The cells were then analyzed by flow cytometry (Becton Dickinson, USA). A minimum of 10,000 events were counted per sample.

2.6. Western Blot Analysis. Cells were collected after drug treatment, and whole cell lysates were prepared by incubation in RIPA buffer (Cell Signaling Technology, Boston, MA, USA) supplemented with a protease inhibitor cocktail (Roche), according to the manufacturer's instructions. The lysates $(20 \mu \mathrm{g}$ protein) were separated by SDS-PAGE $(6 \%-$ $12 \%)$ and transferred to polyvinylidene fluoride membranes. After blocking the membranes with 5\% nonfat dry milk, primary antibodies (1:500 dilution) were added, and the membranes were incubated for $2 \mathrm{~h}$ at room temperature, followed by incubation with the corresponding anti-rabbit IgG, HRP-linked secondary antibodies at room temperature for $1 \mathrm{~h}$. Extensive washes were performed between each step. Bound antibodies were visualized using the ECL Advance western blotting detection kit (GE Healthcare, Little Chalfont, Buckinghamshire, UK), and images were obtained using the LAS-4000 imaging system (Fuji Film, Tokyo, Japan).

2.7. Statistical Analysis. The data are expressed as mean \pm standard deviation (S.D.). Groups were compared by Student's $t$-test and analysis of variance; $P<0.05$ was considered significant.

\section{Results}

3.1. Icariin Increased Viability of PC12 Cells Treated with $A \beta_{25-35}$. Because $\mathrm{A} \beta$ has been shown to induce neuronal apoptosis in the pathogenesis of $\mathrm{AD}$, we evaluated the effect of $\mathrm{A} \beta_{25-35}$ on PC12 cell viability. Cultures were treated with 10 , 20 , 30, or $40 \mu \mathrm{m} \mathrm{A} \beta_{25-35}$, and cell viability was determined $24 \mathrm{~h}$ later using the MTT assay. As shown in Figure 1, $20 \mu \mathrm{m} \mathrm{A} \beta_{25-35}$ significantly decreased PC12 cell viability, and treatment with $40 \mu \mathrm{m} \mathrm{A} \beta_{25-35}$ resulted in the minimal survival of $25.5 \%$ compared with vehicle-treated controls, indicating a dose-dependent effect.

To evaluate the effects of icariin on $\mathrm{A} \beta_{25-35}$-induced cytotoxicity, we pretreated PC12 cells with 2.5, 5.0, 10.0, or $20.0 \mu \mathrm{m}$ icariin $1 \mathrm{~h}$ prior to $24 \mathrm{~h}$ treatment with $20 \mu \mathrm{m}$ $\mathrm{A} \beta_{25-35}$. Our results show that, at doses $\geq 5.0 \mu \mathrm{m}$, icariin protected cells against the toxic effects of $\mathrm{A} \beta_{25-35}$ (Figure 1). Thus, icariin attenuates the effects of $\mathrm{A} \beta_{25-35}$ on cell viability in a dose-dependent manner.

3.2. Icariin Decreased $A \beta_{25-35}$-Induced Apoptosis in PC12 Cells. The proapoptotic effects of $\mathrm{A} \beta_{25-35}$ were then assessed by Annexin V/PI double staining. Our data showed that $10 \mu \mathrm{m} \mathrm{A} \beta_{25-35}$ was sufficient to induce PC12 cell apoptosis (Figure 2). Consistent with results of the MTT assay, $\mathrm{A} \beta_{25-35}$ increased apoptosis in a dose-dependent manner.

Results of Annexin V/PI staining revealed that icariin is able to prevent $\mathrm{A} \beta_{25-35}$-induced apoptosis in PC12 cells. As shown in Figure 2, $20 \mu \mathrm{m} \mathrm{A} \beta_{25-35}$ increased both early and 


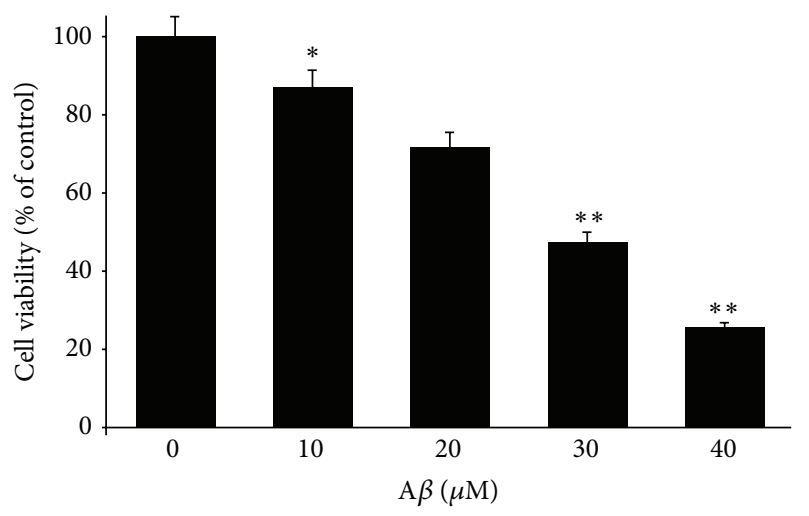

(a)

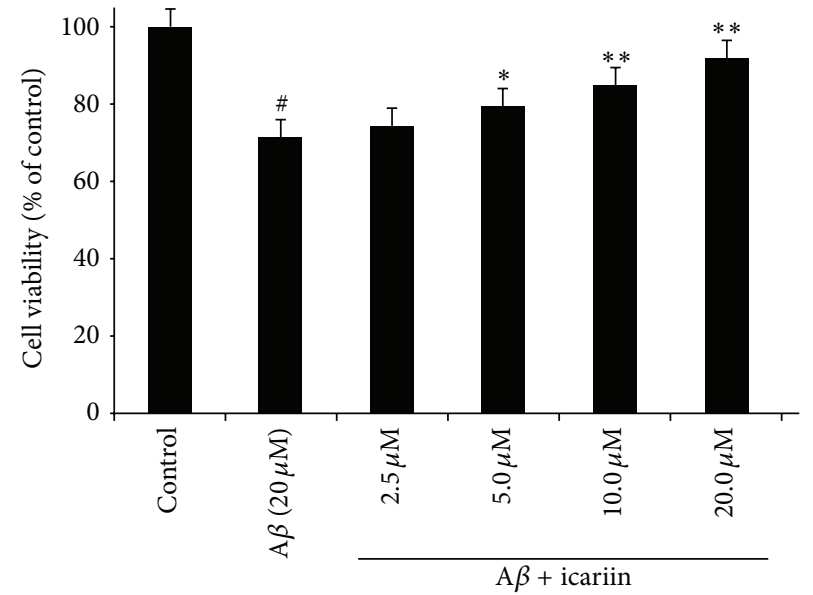

(b)

FIGURE 1: Icariin protects against $\mathrm{A} \beta_{25-35}$-induced cytotoxicity in PC12 cells. (a) Effects of $\mathrm{A} \beta_{25-35}$ on cell viability. PC12 cells were treated with 10-40 $\mu \mathrm{M} \mathrm{A} \beta_{25-35}$, and cell viability was assessed by the MTT assay. (b) Protective effect of icariin against A $\beta_{25-35}$-induced cytotoxicity in PC1 2 cells. After $1 \mathrm{~h}$ pretreatment with icariin $(2.5,5,10$, or $20 \mu \mathrm{M})$, PC12 cells were treated with $20 \mu \mathrm{M} \mathrm{A} \beta_{25-35}$ for 24 h. Results are presented as mean \pm S.D. of five independent experiments. ${ }^{*} P<0.05 ;{ }^{* *} P<0.01$ versus $\mathrm{A} \beta_{25-35}$ treatment; ${ }^{\#} P<0.01$ versus untreated control.

late apoptosis in $\mathrm{PC} 12$ cells, with a total apoptosis rate of $15.8 \%$ by $24 \mathrm{~h}$. However, pretreatment with icariin for $1 \mathrm{~h}$ prior to $\mathrm{A} \beta_{25-35}$ exposure decreased the apoptosis rate to $15.0 \%$ (2.5 $\mu \mathrm{m}$ icariin), $11.0 \%(5.0 \mu \mathrm{m}), 10.2 \%(10 \mu \mathrm{m})$, and $6.6 \%$ $(20 \mu \mathrm{m})$, respectively. The apoptosis rate of cells treated with $2.5 \mu \mathrm{M}$ icariin did not differ significantly from that of controls treated with $\mathrm{A} \beta_{25-35}$ only. These results indicate that icariin dose-dependently suppresses $\mathrm{A} \beta_{25-35}$-induced apoptosis.

\subsection{Role of PI3K/Akt Signaling in the Protective Effect of Icariin} against $A \beta_{25-35}$-Induced Apoptosis. PI3K/Akt signaling plays a pivotal role in cell survival, and its activation may have antiapoptotic effects. We therefore treated PC12 cells with PI3K inhibitor LY294002 $(50 \mu \mathrm{m})$ and found the LY294002 increased apoptosis and decreased viability in PC12 cells treated with $\mathrm{A} \beta_{25-35}$ (Figure 3 ). This result suggests that the $\mathrm{PI} 3 \mathrm{~K} / \mathrm{Akt}$ signaling pathway is involved in $\mathrm{A} \beta_{25-35}$-induced apoptosis. To confirm the role of PI3K/Akt signaling in the neuroprotective effects of icariin, $\mathrm{PC1} 2$ cells were pretreated with $50 \mu \mathrm{mL}$ Y294002 for $30 \mathrm{~min}$, followed by $30 \mathrm{~min}$ treatment with icariin $(20 \mu \mathrm{m})$ and then $24 \mathrm{~h}$ treatment with $20 \mu \mathrm{m} \mathrm{A} \beta_{25-35}$. Our results show that LY294002 diminished the effects of icariin on $\mathrm{A} \beta_{25-35}$-induced apoptosis.

3.4. Icariin Activates the PI3K/Akt Signaling Pathway through Akt Activation. To further investigate the role of PI3K/Akt signaling in the protective effects of icariin against $\mathrm{A} \beta_{25-35^{-}}$ induced apoptosis, we evaluated Akt activation by western blot analysis using phosphorylation state-specific antibodies. A previous study reported that icariin suppresses apoptosis by activating the PI3K/Akt pathway through the phosphorylation of Akt (Ser473) [23]. Our results show that $A \beta_{25-35}$ significantly inhibited Akt phosphorylation, but pretreatment with icariin attenuated the effects of $\mathrm{A} \beta_{25-35}$, indicating that icariin activates the PI3K/Akt pathway (Figure 4). LY294002 significantly inhibited the effects of icariin treatment, providing additional evidence for the role of PI3K/Akt signaling in the protective effects of icariin.

3.5. Icariin Attenuates Bax and Caspase-3 Expression through PI3K/Akt Signaling. The major executioners of apoptosis are the proteases caspase-3 and Bax. Activation of PI3K/Akt directly and indirectly induces the phosphorylation of Bax and caspase-3, promoting their interactions with other proteins and inhibiting apoptotic activity. As shown in Figures 5 and 6, protein levels of caspase-3 and Bax were significantly increased by $\mathrm{A} \beta_{25-35}$ treatment, compared with untreated controls. However, results of western blotting show that icariin decreased levels of caspase-3 and Bax in $\mathrm{A} \beta_{25-35^{-}}$ treated cells. PI3K inhibitor LY294002 attenuated the effects of icariin, indicating that icariin inhibits expression of Bax and caspase- 3 through the activation of PI3K/Akt signaling.

3.6. Icariin Stimulates Bcl-2 Expression via the PI3K/Akt Pathway. Because activation of the PI3K/Akt pathway is known to upregulate $\mathrm{Bcl}-2$ and prevent apoptosis, we next evaluated the effects of icariin on Bcl-2 expression. As shown in Figure 7 , icariin attenuated the $\mathrm{A} \beta_{25-35}$-induced decrease in $\mathrm{Bcl}-2$ protein levels, but the effect of icariin on Bcl-2 was diminished by LY294002. This result provides further evidence for the role of PI3K/Akt signaling in the antiapoptotic effects of icariin.

\section{Discussion}

Extensive cell death is one of the most important pathological manifestations of AD [25-28]. Although the causal events remain unclear, preventing neuronal cell death is a promising approach to treating AD [29]. The purpose of this study was to better understand the neuroprotective effects 


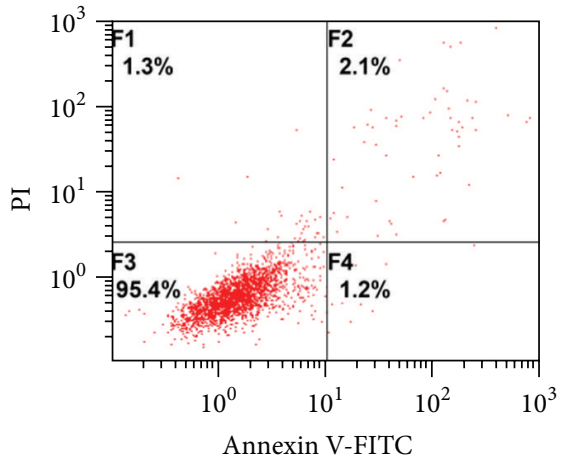

(A)

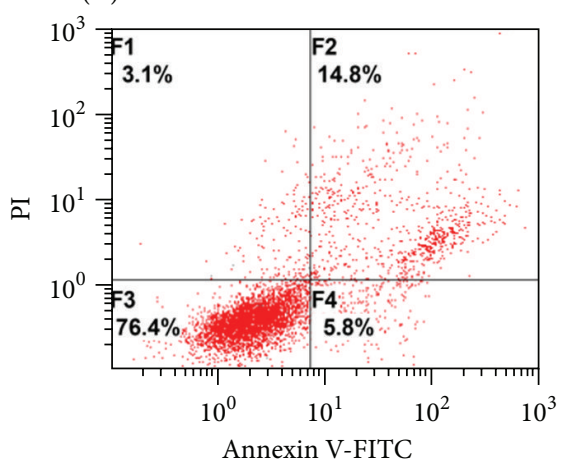

(D)

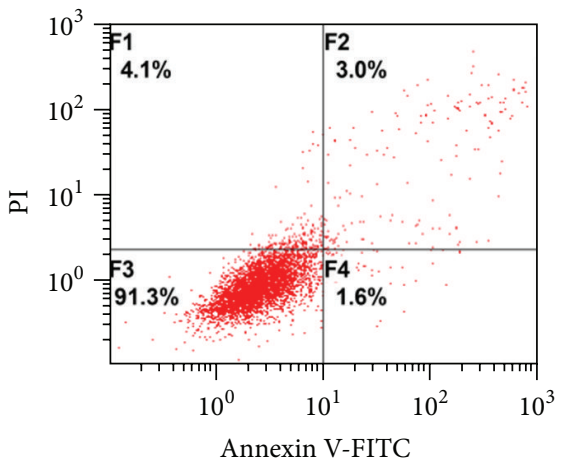

(B)

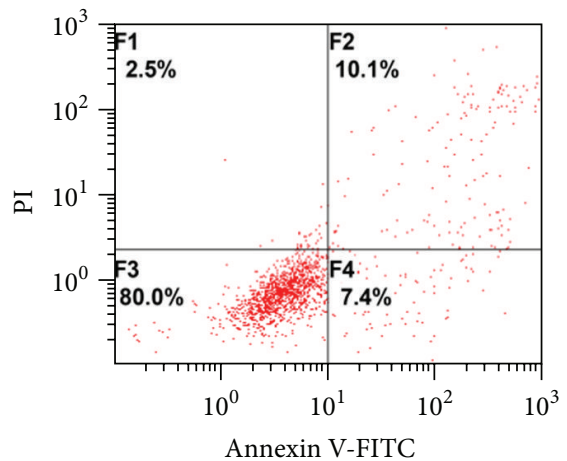

(C)

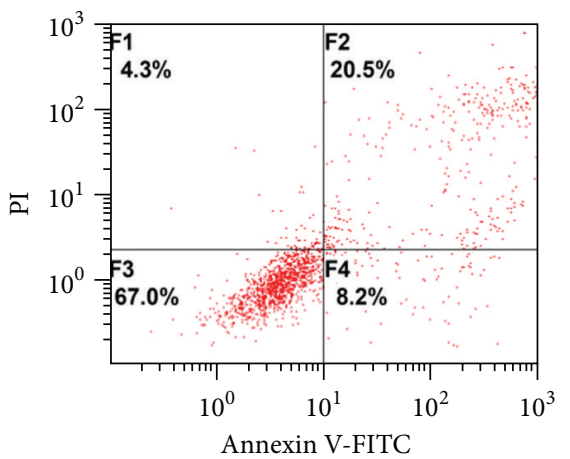

(E)

(a)
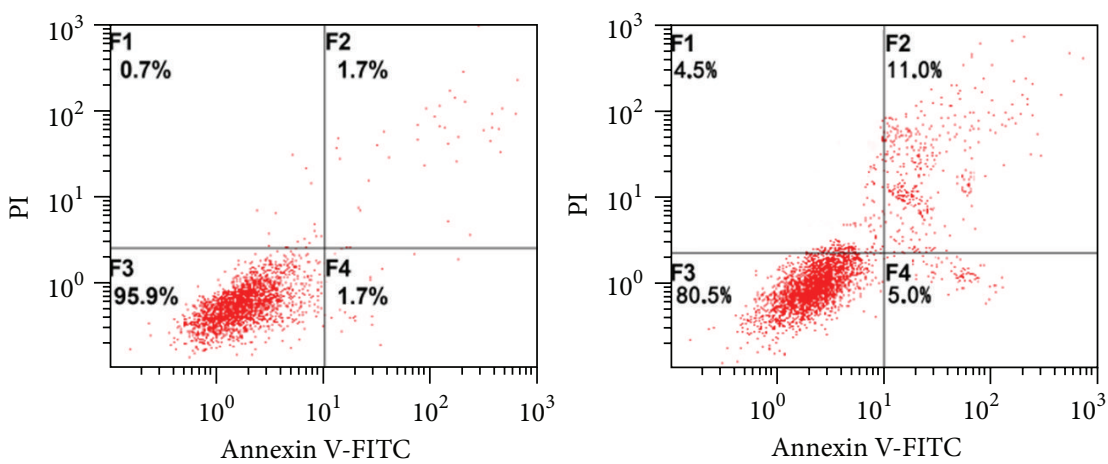

(B)

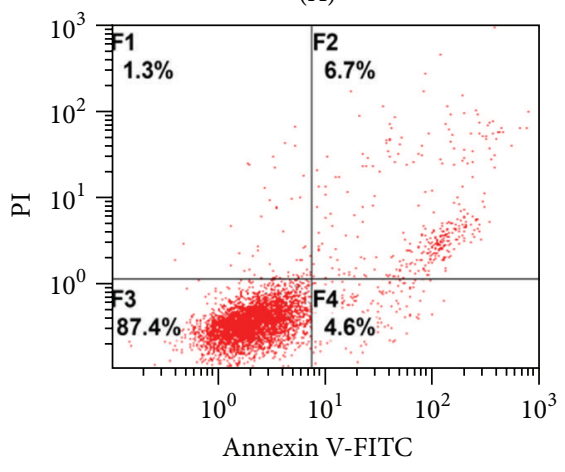

(D)

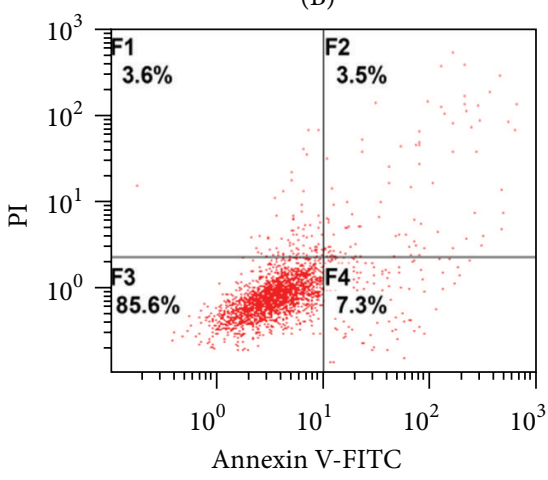

(E)

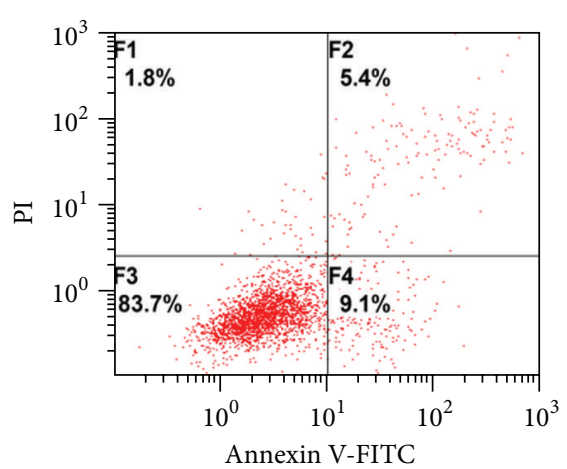

(C)

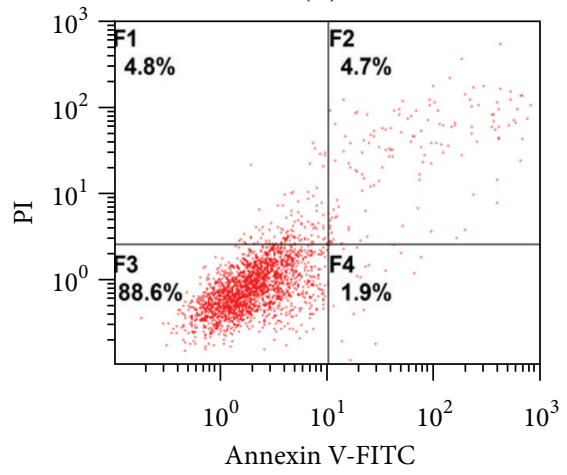

(F)

(b)

Figure 2: Protective effects of icariin on $\mathrm{A} \beta_{25-35}$-induced apoptosis in PC12 cells. (a) Proapoptotic effect of $\mathrm{A} \beta_{25-35}$. After treatment with the following concentrations of $\mathrm{A} \beta_{25-35}$, cell apoptosis was evaluated by Annexin V/PI staining: (A) $0 \mu \mathrm{M}$, (B) $10 \mu \mathrm{M}$, (C) $20 \mu \mathrm{M}$, (D) $30 \mu \mathrm{M}$, or (E) $40 \mu \mathrm{M}$. (b) Protective effect of icariin against $\mathrm{A} \beta_{25-35}$-induced apoptosis. After $1 \mathrm{~h}$ pretreatment with icariin $(0,2.5,5,10$, or $20 \mu \mathrm{M}), \mathrm{PC} 12$ cells were treated with $20 \mu \mathrm{M} \mathrm{A} \beta_{25-35}$ for $24 \mathrm{~h}$. Apoptosis was evaluated by Annexin V/PI staining. (A) Untreated control, (B) $20 \mu \mathrm{M}$ A $\beta_{25-35}$ only, (C) $2.5 \mu \mathrm{M}$ icariin, (D) $5 \mu \mathrm{M}$ icariin, (E) $10 \mu \mathrm{M}$ icariin, and (F) $20 \mu \mathrm{M}$ icariin. Apoptosis rates are shown in Supplementary Figure 1 (available online at http://dx.doi.org/10.1155/2015/235265). 


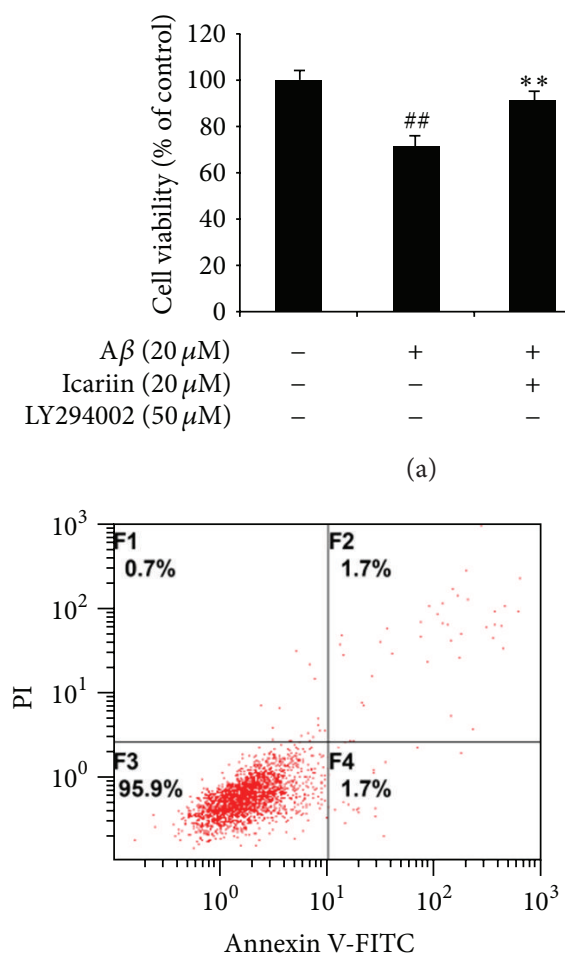

(A)

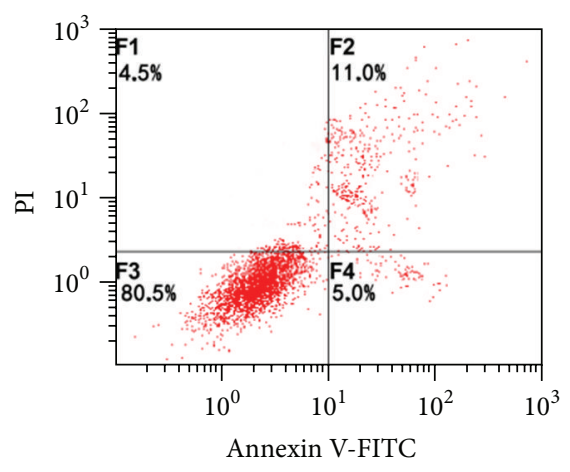

(B)

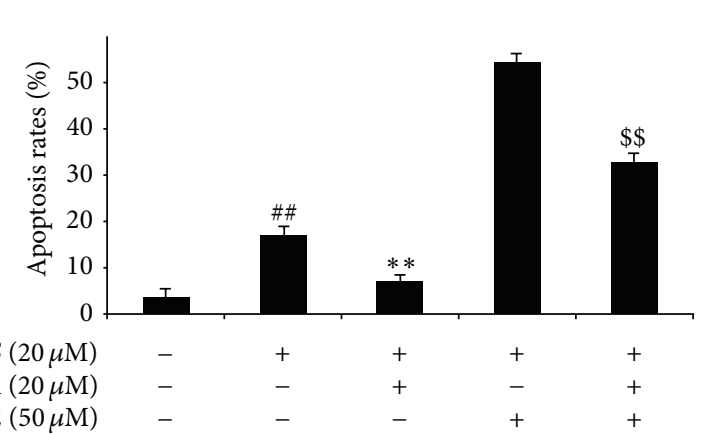

(b)

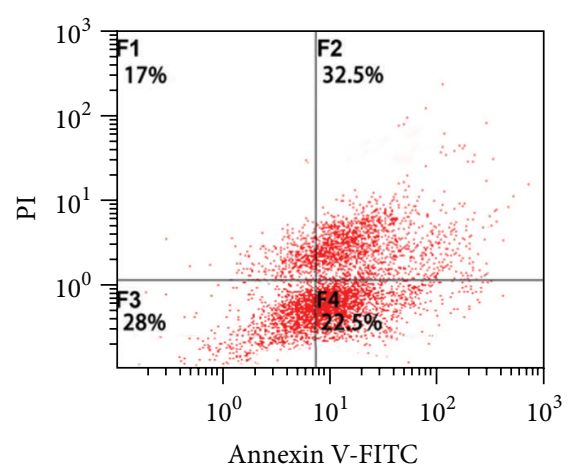

(D)

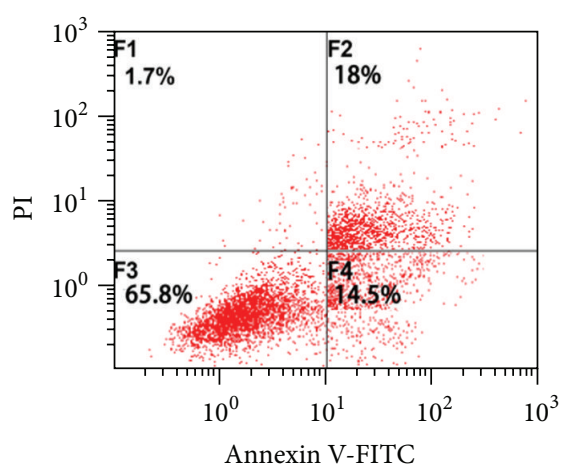

(E)

(c)

FIGURE 3: Involvement of PI3K/Akt signaling in the protective effects of icariin against $\mathrm{A} \beta_{25-35}$-induced cytotoxicity in PC12 cells. After $1 \mathrm{~h}$ pretreatment with the PI3K inhibitor LY294002 (50 $\mu \mathrm{M})$, PC12 cells were treated with $20 \mu \mathrm{M}$ icariin for $1 \mathrm{~h}$, followed by A $\beta_{25-35}$ treatment for $24 \mathrm{~h}$. Cell viability and apoptosis were determined by MTT assay and Annexin V/PI double staining, respectively. (a) LY294002 inhibited the icariin-mediated increase in viability in A $\beta_{25-35}$-treated cells. (b) LY294002 inhibited the icariin-mediated decrease in apoptosis in A $\beta_{25-35^{-}}$ treated cells. (c) (A) Untreated control, (B) A $\beta_{25-35}$ treatment, (C) icariin treatment, (D) LY294002 treatment, and (E) icariin + LY294002. Results are presented as mean \pm S.D. of triplicate independent experiments. ${ }^{\# \#} P<0.01$ versus untreated control; ${ }^{* *} P<0.01$ versus $A \beta_{25-35}$ treatment; ${ }^{\$ \$} P<0.01$ versus icariin treatment.

of icariin against $A \beta$ neurotoxicity and identify the signaling pathways involved. Because activation of the PI3K/Akt pathway promotes cell survival [12], we assessed the role of PI3K/Akt signaling in the protective effects of icariin. First, we demonstrated that $\mathrm{A} \beta_{25-35}$ decreased PC12 cell viability and increased apoptosis in a dose-dependent manner. Pretreatment with icariin dose-dependently increased viability and decreased apoptosis in $\mathrm{A} \beta_{25-35}$-treated cells. These findings are consistent with a previous study reporting that icariin prevents cell death associated with $\mathrm{A} \beta$ toxicity [23].

The PI3K/Akt signaling pathway plays a crucial role in cell survival by inhibiting apoptosis [30, 31]. Recent studies suggest that activation of PI3K/Akt signaling attenuates $A \beta$-induced apoptosis through the inhibition of glycogen synthase kinase- 3 beta, which suppresses tau protein hyperphosphorylation and the formation of neurofibrillary tangles $[32,33]$. Recent studies have also reported 


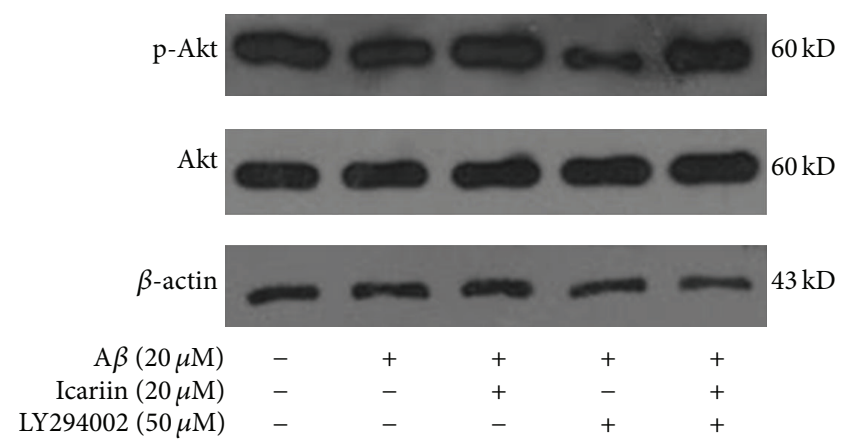

(a)

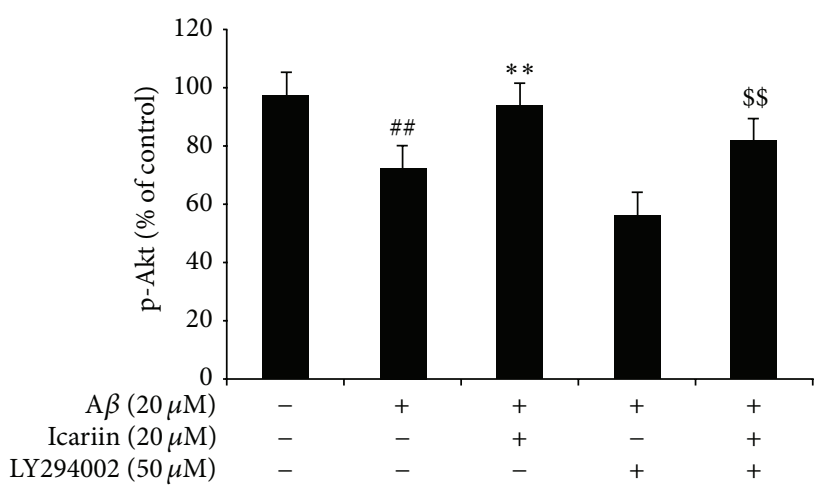

(b)

FIGURE 4: Icariin inhibits $\mathrm{A} \beta_{25-35}$-induced cytotoxicity through the activation of PI3K/Akt signaling. After $1 \mathrm{~h}$ pretreatment with the PI3K inhibitor LY294002 $(50 \mu \mathrm{M})$, PC12 cells were treated with $20 \mu \mathrm{M}$ icariin for $1 \mathrm{~h}$, followed by A $\beta_{25-35}$ treatment for $24 \mathrm{~h}$. Phosphorylation of Akt was assessed by western blot. Densitometry values represent the mean \pm S.D. of triplicate independent experiments. ${ }^{\# \#} P<0.01$ versus untreated control; ${ }^{* *} P<0.01$ versus $\mathrm{A} \beta_{25-35}$ treatment; ${ }^{\$ \$} P<0.01$ versus icariin treatment.

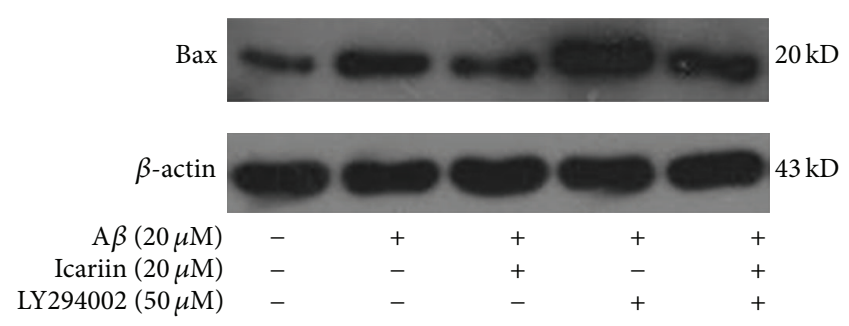

(a)

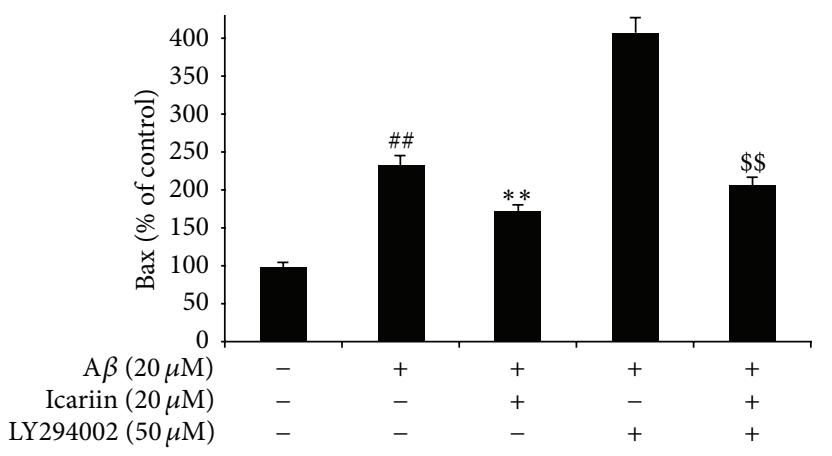

(b)

FIGURE 5: Icariin decreased Bax expression in PC12 cells after exposure to A $\beta_{25-35}$. After pretreatment with $50 \mu \mathrm{M} \mathrm{LY} 294002$ for $1 \mathrm{~h}$, PC12 cells were treated with $20 \mu \mathrm{M}$ icariin for $1 \mathrm{~h}$, followed by $\mathrm{A} \beta_{25-35}$ treatment for $24 \mathrm{~h}$. Densitometry values are presented as the mean \pm S.D. of triplicate independent experiments. ${ }^{\# \#} P<0.01$ versus untreated control; ${ }^{* *} P<0.01$ versus $\mathrm{A} \beta_{25-35}$ treatment; ${ }^{\$ \$} P<0.01$ versus icariin treatment.

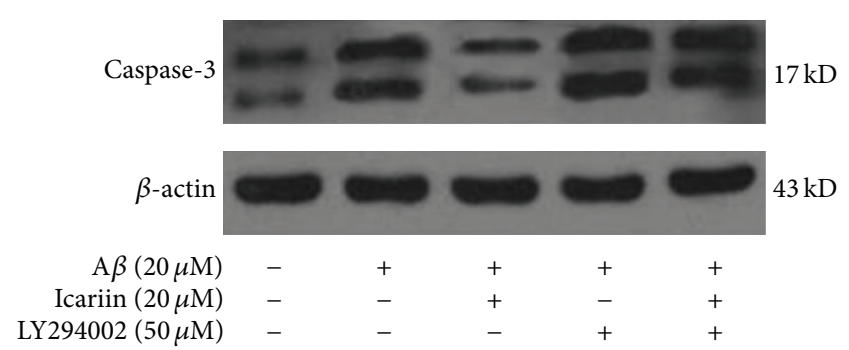

(a)

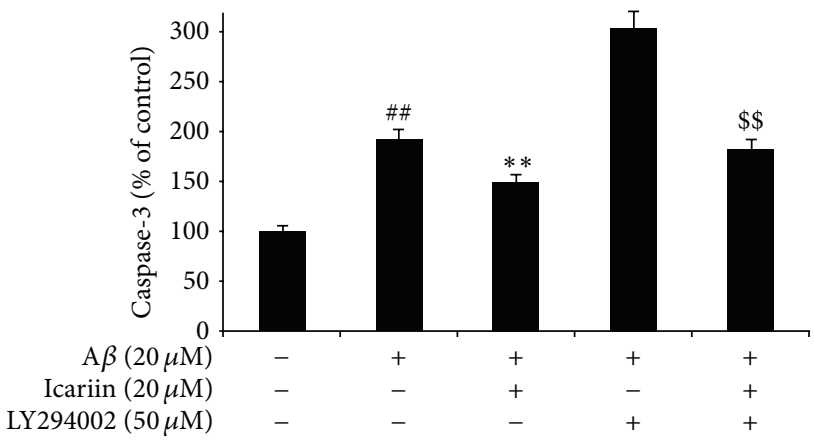

(b)

FIGURE 6: Icariin decreased caspase-3 expression in PC12 cells after exposure to A $\beta_{25-35}$. After pretreatment with $50 \mu \mathrm{M}$ LY294002 for $1 \mathrm{~h}$, PC12 cells were treated with $20 \mu \mathrm{M}$ icariin for $1 \mathrm{~h}$, followed by A $\beta_{25-35}$ treatment for 24 h. Densitometry values are presented as the mean \pm S.D. of triplicate independent experiments. ${ }^{\# \#} P<0.01$ versus control; ${ }^{* *} P<0.01$ versus $\mathrm{A} \beta_{25-35}$ treatment; ${ }^{\$ \$} P<0.01$ versus icariin treatment. 


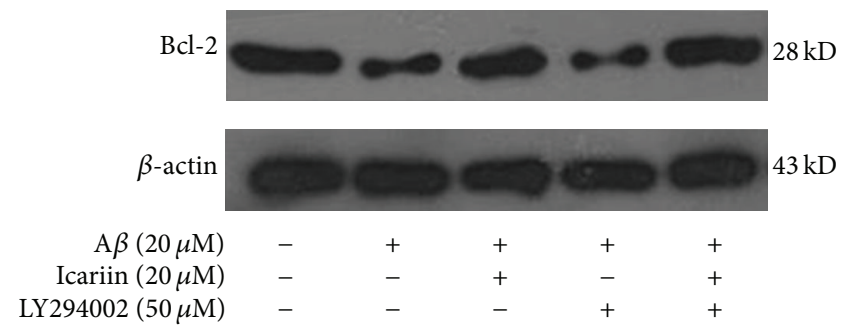

(a)

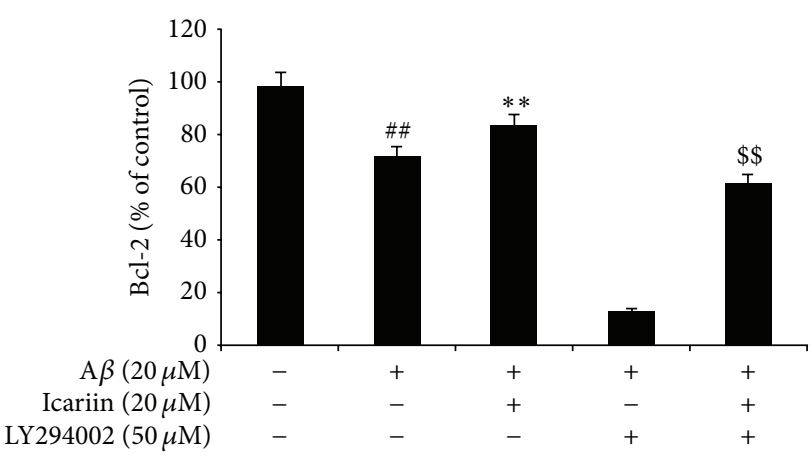

(b)

Figure 7: Icariin increased Bcl-2 protein levels in PC12 cells exposed to A $\beta_{25-35}$. After pretreatment with $50 \mu \mathrm{M} \mathrm{LY} 294002$ for $1 \mathrm{~h}, \mathrm{PC1} 2$ cells were treated with $20 \mu \mathrm{M}$ icariin for $1 \mathrm{~h}$, followed by $24 \mathrm{~h} \mathrm{~A} \beta_{25-35}$ treatment. Densitometry values are presented as mean \pm S.D. of triplicate independent experiments. ${ }^{\# \#} P<0.01$ versus control; ${ }^{* *} P<0.01$ versus $\mathrm{A} \beta_{25-35}$ treatment; ${ }^{\$ \$} P<0.01$ versus icariin treatment.

that icariin inhibits corticosterone-induced apoptosis [24] and lipopolysaccharide-induced inflammation through the PI3K/Akt pathway [34]. Cai et al. suggested that the protective effects of icariin against $\mathrm{A} \beta$ neurotoxicity depend on the insulin/insulin-like growth factor 1 pathway [35], which is upstream of the PI3K/Akt pathway [36]. Our results demonstrating that icariin increased viability and decreased apoptosis in $\mathrm{A} \beta$-treated PC12 cells and that these effects were attenuated by a PI $3 \mathrm{~K}$ inhibitor strongly support a role for this signaling pathway in icariin-mediated neuroprotection.

Because icariin has been reported to activate PI3K/Akt signaling through the phosphorylation of Akt (Ser473) [23], we evaluated Akt phosphorylation in icariin-treated PC12 cells. The results of western blot analysis confirmed that icariin significantly increased phosphorylation of Akt at Ser473, and that this effect was suppressed by LY294002, providing further evidence that icariin suppresses apoptosis through activation of PI3K/Akt signaling.

PI3K/Akt signaling promotes cell survival by direct or indirect interaction with proteins associated with apoptosis [12], such as Bcl-2, which promotes cell survival [37], and Bax, which promotes mitochondrial permeability leading to apoptosis [13]. Activated Akt directly or indirectly suppresses the apoptotic activity of Bax by serine phosphorylation [13]. Caspase- 3 is activated by exposure to $\mathrm{A} \beta$ peptides, contributing to the pathophysiology of $\mathrm{AD}$ through cell death-independent mechanisms, as well as apoptosis $[38,39]$. We found that icariin attenuated the effects of $\mathrm{A} \beta_{25-35}$ in PC12 cells, increasing protein levels of prosurvival factor Bcl2 and decreasing protein levels of proapoptotic factors Bax and caspase-3. PI3K inhibitor LY294002 suppressed these effects of icariin.

The extracellular signal-regulated protein kinase (ERK) pathway may also play an important role in the antiapoptotic effects of icariin. ERK, which is a converging point of multiple signal transduction pathways involved in apoptosis [40], has been shown to decrease $b c l-2$ gene expression through the tumor suppressor p53 [40]. In addition, Akt may act synergistically with p90 ribosomal S6 kinase to inhibit the proapoptotic activity of Bax through phosphorylation [13].
Although several studies have reported that icariin promotes cell proliferation by activating ERK [41, 42], another study suggested that icariin inhibits corticosterone-induced apoptosis in primary cultured rat hippocampal neurons by blocking p38 mitogen-activated protein kinase but not ERK [43]. Therefore, further research is needed to clarify the role of ERK in the neuroprotective effects of icariin.

In conclusion, this study provides evidence that icariin is effective in suppressing $\mathrm{A} \beta_{25-35}$-induced apoptosis in PC12 cells, which likely occurs through the activation of PI3K/Akt signaling. Our results also indicate that icariin upregulates Bcl-2 and downregulates Bax, two critical downstream effectors in PI3K/Akt signaling. Further studies are needed to better understand the cellular mechanisms underlying the neuroprotective effects of icariin, which may ultimately lead to the development of a novel therapy for the treatment of $\mathrm{AD}$.

\section{Conflict of Interests}

The authors certify that they do not have a direct financial relationship with the companies mentioned in their paper and have no other conflict of interests in connection with the submitted paper.

\section{Acknowledgments}

This work was supported by the National Natural Science Foundation of China (no. 8137370); Natural Science Foundation of Hunan Province (no. 13JJ3030); Special Project of High-Tech Industrial Development of Hunan Province (no. 2012SK3212); and Traditional Chinese Medicine Science Research Foundation of the Health Department of Hunan Province (no. 2013146).

\section{References}

[1] C. Reitz, C. Brayne, and R. Mayeux, "Epidemiology of Alzheimer disease," Nature Reviews Neurology, vol. 7, no. 3, pp. 137-152, 2011. 
[2] Y. Huang and L. Mucke, "Alzheimer mechanisms and therapeutic strategies," Cell, vol. 148, no. 6, pp. 1204-1222, 2012.

[3] C. Ballard, S. Gauthier, A. Corbett, C. Brayne, D. Aarsland, and E. Jones, "Alzheimer's disease," The Lancet, vol. 377, no. 9770, pp. 1019-1031, 2011.

[4] E. Karran, M. Mercken, and B. D. Strooper, "The amyloid cascade hypothesis for Alzheimer's disease: an appraisal for the development of therapeutics," Nature Reviews Drug Discovery, vol. 10, no. 9, pp. 698-712, 2011.

[5] J. Hardy and D. J. Selkoe, "The amyloid hypothesis of Alzheimer's disease: progress and problems on the road to therapeutics," Science, vol. 297, no. 5580, pp. 353-356, 2002.

[6] A. Serrano-Pozo, M. P. Frosch, E. Masliah, and B. T. Hyman, "Neuropathological alterations in Alzheimer disease," Cold Spring Harbor Perspectives in Medicine, vol. 1, no. 1, Article ID a006189, 2011.

[7] C. Behl, "Apoptosis and Alzheimer's disease," Journal of Neural Transmission, vol. 107, no. 11, pp. 1325-1344, 2000.

[8] M. Ankarcrona and B. Winblad, "Biomarkers for apoptosis in Alzheimer's disease," International Journal of Geriatric Psychiatry, vol. 20, no. 2, pp. 101-105, 2005.

[9] P. Calissano, C. Matrone, and G. Amadoro, "Apoptosis and in vitro Alzheimer disease neuronal models," Communicative and Integrative Biology, vol. 2, no. 2, pp. 163-169, 2009.

[10] A. Camins, M. Pallàs, and J. S. Silvestre, "Apoptotic mechanisms involved in neurodegenerative diseases: experimental and therapeutic approaches," Methods and Findings in Experimental and Clinical Pharmacology, vol. 30, no. 1, pp. 43-65, 2008.

[11] M. Vila and S. Przedborski, "Targeting programmed cell death in neurodegenerative diseases," Nature Reviews Neuroscience, vol. 4, no. 5, pp. 365-375, 2003.

[12] G. Song, G. Ouyang, and S. Bao, "The activation of Akt/PKB signaling pathway and cell survival," Journal of Cellular and Molecular Medicine, vol. 9, no. 1, pp. 59-71, 2005.

[13] J. Yuan and B. A. Yankner, "Apoptosis in the nervous system," Nature, vol. 407, no. 6805, pp. 802-809, 2000.

[14] S. C. Wing Sze, Y. Tong, T. B. Ng, C. L. Yin Cheng, and H. P. Cheung, "Herba Epimedii: anti-oxidative properties and its medical implications," Molecules, vol. 15, no. 11, pp. 7861-7870, 2010.

[15] J. Guo, F. Li, Q. Wu, Q. Gong, Y. Lu, and J. Shi, "Protective effects of icariin on brain dysfunction induced by lipopolysaccharide in rats," Phytomedicine, vol. 17, no. 12, pp. 950-955, 2010.

[16] S. Li, P. Dong, J. Wang et al., "Icariin, a natural flavonol glycoside, induces apoptosis in human hepatoma SMMC7721 cells via a ROS/JNK-dependent mitochondrial pathway," Cancer Letters, vol. 298, no. 2, pp. 222-230, 2010.

[17] J. Zhou, J. Wu, X. Chen et al., "Icariin and its derivative, ICT, exert anti-inflammatory, anti-tumor effects, and modulate myeloid derived suppressive cells (MDSCs) functions," International Immunopharmacology, vol. 11, no. 7, pp. 890-898, 2011.

[18] Z. Wang, X. Zhang, H. Wang, L. Qi, and Y. Lou, "Neuroprotective effects of icaritin against beta amyloid-induced neurotoxicity in primary cultured rat neuronal cells via estrogendependent pathway," Neuroscience, vol. 145, no. 3, pp. 911-922, 2007.

[19] L. Yang, D. Lu, J. Guo, X. Meng, G. Zhang, and F. Wang, "Icariin from Epimedium brevicornum Maxim promotes the biosynthesis of estrogen by aromatase (CYP19)," Journal of Ethnopharmacology, vol. 145, no. 3, pp. 715-721, 2013.
[20] J. Nie, Y. Luo, X.-N. Huang, Q.-H. Gong, Q. Wu, and J.-S. Shi, "Icariin inhibits beta-amyloid peptide segment 25-35 induced expression of beta-secretase in rat hippocampus," European Journal of Pharmacology, vol. 626, no. 2-3, pp. 213-218, 2010.

[21] T. Urano and C. Tohda, "Icariin improves memory impairment in Alzheimer's disease model mice (5xFAD) and attenuates amyloid $\beta$-induced neurite atrophy," Phytotherapy Research, vol. 24, no. 11, pp. 1658-1663, 2010.

[22] X.-L. He, W.-Q. Zhou, M.-G. Bi, and G.-H. Du, "Neuroprotective effects of icariin on memory impairment and neurochemical deficits in senescence-accelerated mouse prone 8 (SAMP8) mice," Brain Research, vol. 1334, pp. 73-83, 2010.

[23] K.-W. Zeng, H. Ko, H. O. Yang, and X.-M. Wang, "Icariin attenuates $\beta$-amyloid-induced neurotoxicity by inhibition of tau protein hyperphosphorylation in PC12 cells," Neuropharmacology, vol. 59, no. 6, pp. 542-550, 2010.

[24] H. Zhang, B. Liu, J. Wu et al., "Icariin inhibits corticosteroneinduced apoptosis in hypothalamic neurons via the PI3-K/Akt signaling pathway," Molecular Medicine Reports, vol. 6, no. 5, pp. 967-972, 2012.

[25] J.-H. Lee, Y.-H. Cheon, R.-S. Woo, D.-Y. Song, C. Moon, and T.K. Baik, "Evidence of early involvement of apoptosis inducing factor-induced neuronal death in Alzheimer brain," Anatomy \& Cell Biology, vol. 45, no. 1, pp. 26-37, 2012.

[26] W. Yu, N. Mechawar, S. Krantic, and R. Quirion, "Evidence for the involvement of apoptosis-inducing factor-mediated caspase-independent neuronal death in Alzheimer disease," The American Journal of Pathology, vol. 176, no. 5, pp. 2209-2218, 2010.

[27] A. Eckert, C. A. Marques, U. Keil, K. Schüssel, and W. E. Müller, "Increased apoptotic cell death in sporadic and genetic Alzheimer's disease," Annals of the New York Academy of Sciences, vol. 1010, pp. 604-609, 2003.

[28] G. Smale, N. R. Nichols, D. R. Brady, C. E. Finch, and W. E. Horton Jr., "Evidence for apoptotic cell death in Alzheimer's disease," Experimental Neurology, vol. 133, no. 2, pp. 225-230, 1995.

[29] R. Donev, M. Kolev, B. Millet, and J. Thome, "Neuronal death in Alzheimer's disease and therapeutic opportunities," Journal of Cellular and Molecular Medicine, vol. 13, no. 11-12, pp. 43294348, 2009.

[30] V. Duronio, "The life of a cell: apoptosis regulation by the PI3K/PKB pathway," Biochemical Journal, vol. 415, no. 3, pp. 333-344, 2008.

[31] B. A. Hemmings, "Akt signaling: linking membrane events to life and death decisions," Science, vol. 275 , no. 5300, pp. $628-$ 630, 1997.

[32] H.-K. Lee, P. Kumar, Q. Fu, K. M. Rosen, and H. W. Querfurth, "The insulin/Akt signaling pathway is targeted by intracellular $\beta$-amyloid," Molecular Biology of the Cell, vol. 20, no. 5, pp. 15331544, 2009.

[33] A. Rickle, N. Bogdanovic, I. Volkman, B. Winblad, R. Ravid, and R. F. Cowburn, "Akt activity in Alzheimer's disease and other neurodegenerative disorders," NeuroReport, vol. 15, no. 6, pp. 955-959, 2004.

[34] C.-Q. Xu, B.-J. Liu, J.-F. Wu et al., "Icariin attenuates LPS-induced acute inflammatory responses: involvement of $\mathrm{PI} 3 \mathrm{~K} / \mathrm{Akt}$ and NF $\kappa \mathrm{B}$ signaling pathway," European Journal of Pharmacology, vol. 642, no. 1-3, pp. 146-153, 2010.

[35] W.-J. Cai, J.-H. Huang, S.-Q. Zhang et al., "Icariin and its derivative icariside II extend healthspan via insulin/IGF-1 pathway in C. elegans," PLoS ONE, vol. 6, no. 12, Article ID e28835, 2011. 
[36] B. Vanhaesebroeck, L. Stephens, and P. Hawkins, "PI3K signalling: the path to discovery and understanding," Nature Reviews Molecular Cell Biology, vol. 13, no. 3, pp. 195-203, 2012.

[37] J. M. Adams and S. Cory, "The Bcl-2 protein family: arbiters of cell survival," Science, vol. 281, no. 5381, pp. 1322-1326, 1998.

[38] S. Snigdha, E. D. Smith, G. A. Prieto, and C. W. Cotman, "Caspase-3 activation as a bifurcation point between plasticity and cell death," Neuroscience Bulletin, vol. 28, no. 1, pp. 14-24, 2012.

[39] M. D’Amelio, M. Sheng, and F. Cecconi, "Caspase-3 in the central nervous system: beyond apoptosis," Trends in Neurosciences, vol. 35, no. 11, pp. 700-709, 2012.

[40] S. Cagnol and J. C. Chambard, "ERK and cell death: mechanisms of ERK-induced cell death-apoptosis, autophagy and senescence," FEBS Journal, vol. 277, no. 1, pp. 2-21, 2010.

[41] Y. Nan, X. Zhang, G. Yang et al., "Icariin stimulates the proliferation of rat Sertoli cells in an ERK1/2-dependent manner in vitro," Andrologia, vol. 46, no. 1, pp. 9-16, 2014.

[42] B. H. Chung, J. D. Kim, C. K. Kim et al., "Icariin stimulates angiogenesis by activating the MEK/ERK- and PI3K/Akt/ eNOS-dependent signal pathways in human endothelial cells," Biochemical and Biophysical Research Communications, vol. 376, no. 2, pp. 404-408, 2008.

[43] B. Liu, H. Zhang, C. Xu et al., "Neuroprotective effects of icariin on corticosterone-induced apoptosis in primary cultured rat hippocampal neurons," Brain Research, vol. 1375, pp. 59-67, 2011. 


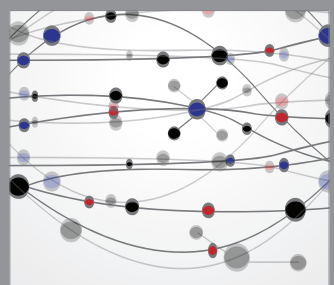

The Scientific World Journal
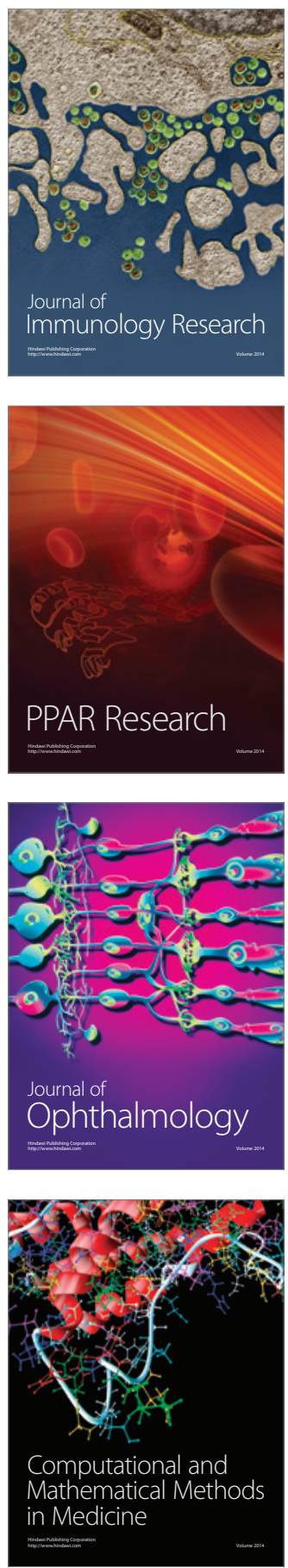

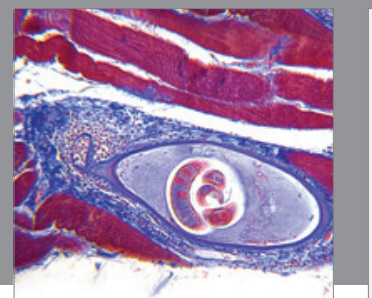

Gastroenterology

Research and Practice
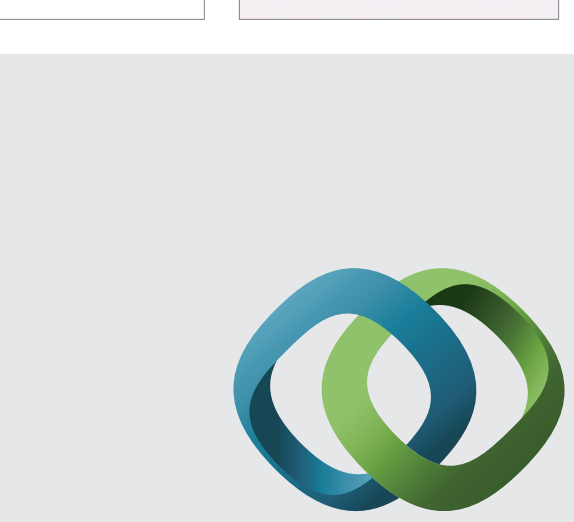

\section{Hindawi}

Submit your manuscripts at

http://www.hindawi.com
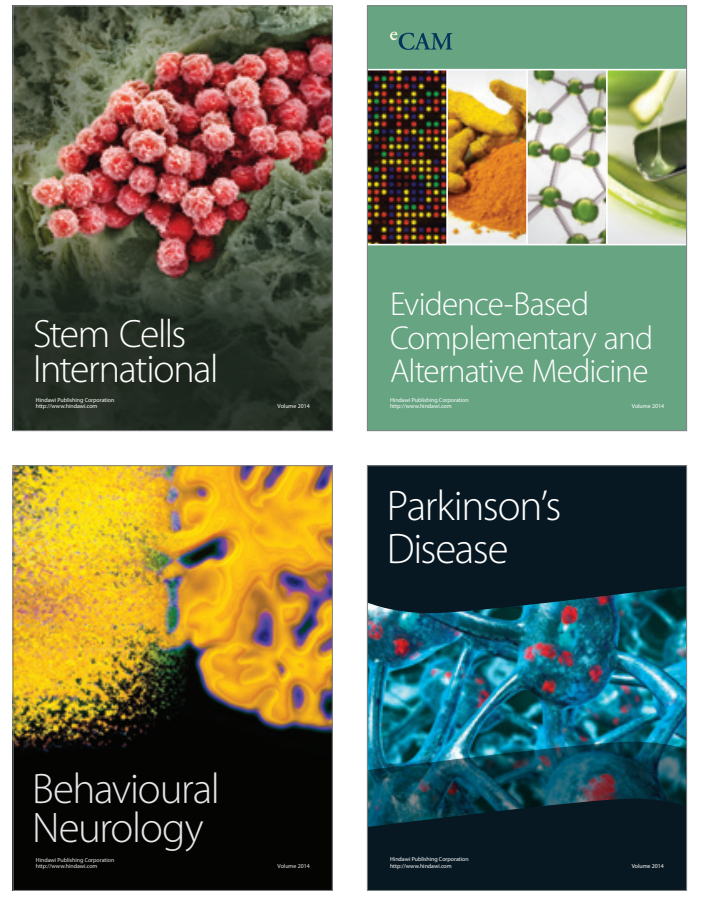
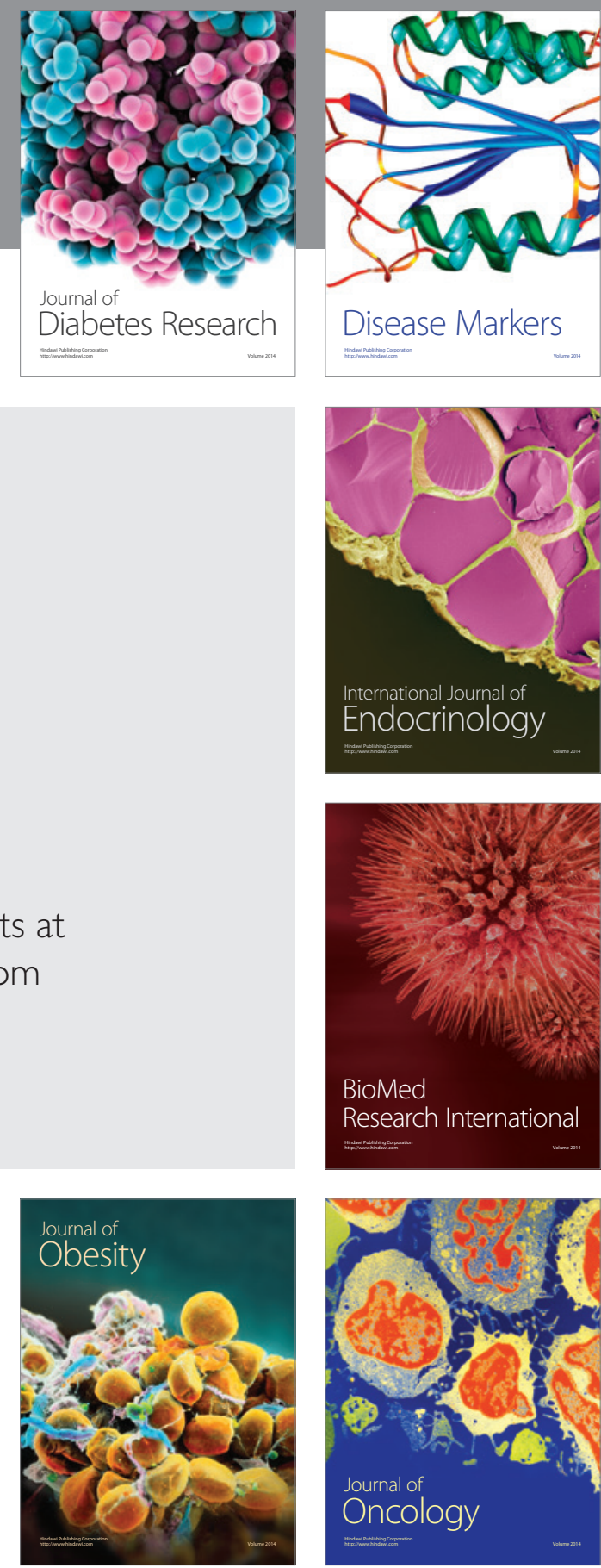

Disease Markers
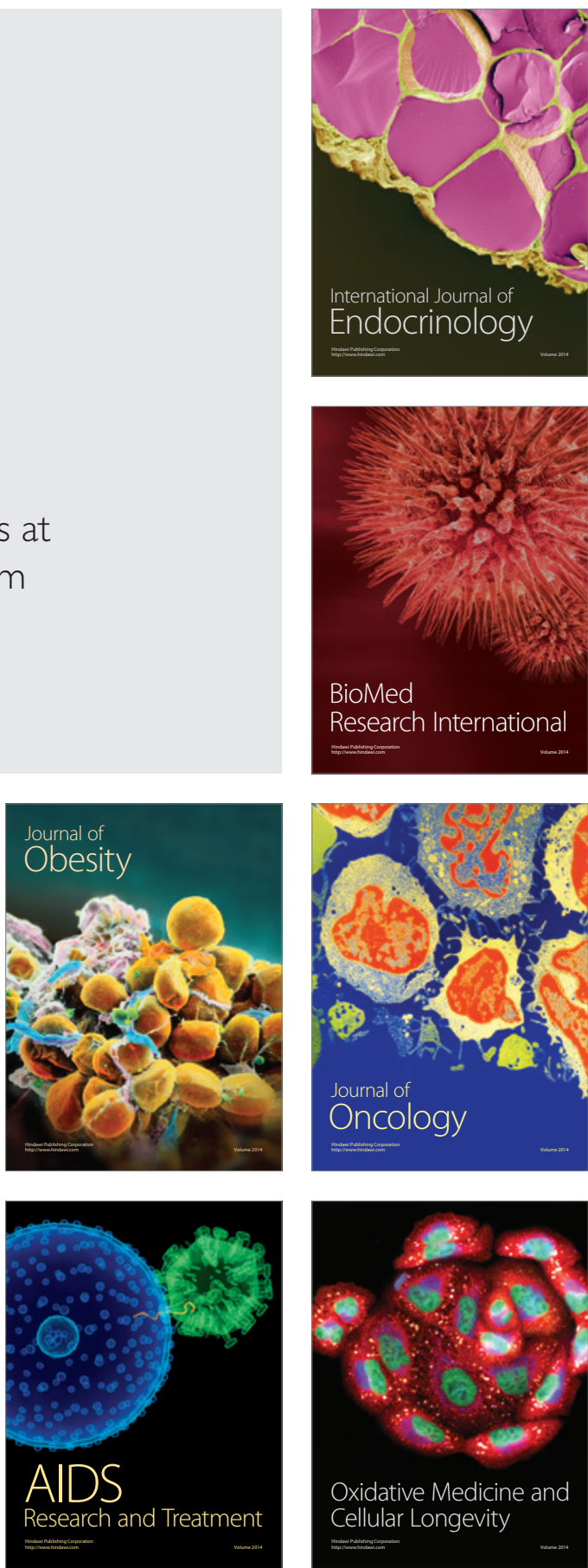